\title{
Fragmentos Menores de Caio Musônio Rufo Gaius Musonius Rufus - Fragmenta Minora
}

\author{
Aldo Dinucci ${ }^{1}$
}

\begin{abstract}
Caio Musônio Rufo, célebre filósofo estoico do primeiro século e professor de Epicteto, era, segundo a Suda², filho de um romano da classe equestre de nome Capito. Suidas também informa ser Musônio tirreno (etrusco), natural de Volsinii, na Etrúria ${ }^{3}$, e ter sido aluno de Hermógenes de Tarso, o sofista ${ }^{4}$. Segundo as cronologias comumente aceitas ${ }^{5}$, teria nascido no fim do reinado de Augusto ou no princípio do de Tibério (por volta do ano 30) e vivido até o reinado dos Flavianos (entre os anos 90 e 100).

Seguiu Rubélio Plauto ${ }^{6}$, quando este foi exilado por $\mathrm{Nero}^{7}$, em $60^{8}$. Retornou a Roma após a morte de Plauto, em 62, mas foi banido por Nero para a ilha de Giaros, em $65^{\circ}$, acusado de ter ocultado a conspiração de Pisão ${ }^{10}$.
\end{abstract}

1 Doutor em Filosofia pela PUC/RJ e professor associado do Departamento de Filosofia da UFS. Coordenador do Grupo de Pesquisa em Filosofia Viva Vox (vivavox.site90.com). Membro permanente do Mestrado em Filosofia da UFS.

2 SUIDAS, Suda, M, 1305.

${ }^{3}$ SUIDAS, Suda, M, 1305. Etrúria, chamada comumente de Tyrrhenia nos textos gregos e latinos: situava-se na região central da Itália, cobrindo parcialmente as áreas das atuais províncias italianas de Toscânia, Lácio, Emília Romana e Úmbria.

4 SUIDAS, Suda, E, 3046.

${ }^{5}$ Cf. KING, 2011, p. 13.

${ }^{6}$ Aristocrata romano e opositor de Nero, por quem foi condenado à morte. Viveu entre 33 e 62 d.C.

7 Imperador de Roma, que governou entre os anos 54 e 68 d.C.

${ }^{8}$ TÁCITO, Anais xiv, 59. Tácito nos diz que os filósofos Musônio e Coeranus da Grécia aconselharam Plauto a aguardar a morte com firmeza, ao invés de levar uma vida precária e ansiosa.

9 Cf. TÁCITO, Anais xv, 71; DION CÁSSIO, lxii; EPICTETO, Diatribes I.25.19-20; II.6.22; III.24.1000 e 109; Philostrato (Vida de Apolônio, vii, 16) ressalta que os gregos iam, por barco, visitar Musônio para ouvir seus discursos; e que, após a partida de Musônio, iam até Giaros para visitar uma fonte de água que teria sido descoberta pelo filósofo na ilha, que, até sua chegada, não tinha fonte de água potável conhecida. Giaros (atual Yioura) é uma ilha desolada do arquipélago grego das Cíclades. Miserável desde a Antiguidade, habitada por uns poucos pescadores, tornou-se posteriormente destino de vários banidos pelos imperadores romanos.

${ }^{10}$ Gneu Calpúrnio Pisão, senador romano que comandou uma conspiração contra Nero, em 65 d.C. 
Com a ascensão de Galba ${ }^{11}$ (ano 68), Musônio retornou do exílio. Tentou, em 69, entre os embaixadores de Vitélio ${ }^{12}$, deter os soldados que marchavam sobre Roma, comandados por Marco Antônio Prius, general de Vespasiano ${ }^{13}$, falando a eles sobre os benefícios da paz, mas não obteve êxito ${ }^{14}$.

Sob Antonino Pio, processou Públio Celer ${ }^{15}$, que, após a conspiração de Pisão, havia denunciado e levado à morte Barea Sorano ${ }^{16}$ (amigo de Musônio), obtendo a condenação ${ }^{17}$. Foi o único filósofo que não foi banido de Roma por Vespasiano em $71^{18}$, mas acabou sendo banido pelo próprio Vespasiano, em 75, retornando após a morte deste, em 79 . Não se sabe a data de sua morte, mas tão somente que não mais vivia sob Trajano, pois Plínio se refere a ele então como já falecido ${ }^{19}$.

Suidas menciona suas obras e as cartas supostamente trocadas entre Musônio e Apolônio de Tiana, consideradas espúrias ${ }^{20}$. Musônio, porém, nada escreveu: dois alunos seus incumbiram-se dessa tarefa: Lucius (do qual nos chegaram 21 diatribes, preservadas por Estobeu ${ }^{21}$ ) e Pólio, cuja obra não nos chegou senão em fragmentos ${ }^{22}$. A edição crítica de sua obra é de autoria de

\footnotetext{
${ }^{11}$ Imperador de Roma, que governou por sete meses entre os anos 68 e 69 d.C.

12 Imperador de Roma, que, tendo assumido o império em 69 d.C., renunciou pouco depois e foi executado pelos soldados de Vespasiano.

13 Imperador de Roma, entre os anos 69 e 70 d.C.

14 TÁCITO, Histórias, iii, 81. Tácito nos diz que "Musônio uniu-se às tropas, e, amplificando as bênçãos da paz e os perigos da guerra, começou a admoestar a multidão armada. Muitos acharam-no ridículo; outros, cansativo; outros estavam prontos para atirá-lo ao chão e pisoteá-lo caso ele não tivesse ouvido os avisos dos mais comportados e as ameaças dos outros e cessado de exibir sua extemporânea sabedoria”.
}

15 Filósofo estoico que, tendo sido informante de Nero, foi condenado à morte e executado sob Vespasiano.

${ }^{16}$ Senador romano condenado à morte por Nero. Suicidou-se em 65 ou 66 d.C.

17 TÁCITO, Histórias, iv, 10; 40. Tácito comenta que Musônio Rufo acusou Públio Celer de ter promovido a destruiçấo de Bareas Sorano por perjúrio. Naquele momento, a memória de Sorano era mantida com reverência. Celer, por outro lado, como professor de filosofia, mas, ao mesmo tempo, amigo e delator de Bareas, era visto como evidentemente culpado.

18 DION CÁSSIO, lxv, 13.

19 PLÍNIO, O JOVEM, Cartas, iii, 11.

${ }^{20}$ FILOSTRATO, Vida de Apolônio de Tiana, iv, 46.

21 ESTOBEU, Florilégio, xxix, 78; lvi, 18.

22 Por exemplo: AULO GÉLIO, v. 1; ix.2; xvi.1. 
Hense $^{23}$, que deve ser complementada por um papiro incluído na edição de Lutz $^{24}$.

Os fragmentos que ora traduzimos são, em sua maioria, gnômicos, tendo como pano de fundo a doutrina moral estoica. Outros revelam que Musônio lidava com conceitos fundamentais da epistemologia estoica. Nos fragmentos 38 e 40, Musônio se refere ao conceito estoico de phantasia (que aqui traduzimos por "representação"). Ainda no fragmento 38, vemos que a doutrina comumente associada a Epicteto, pela qual se distingue entre o que está e o que não está sob nosso controle (cf. Encheirídion de Epicteto, I; Diatribes de Epicteto I.1), já era, na verdade, utilizada por Musônio. No fragmento 40, vemos Musônio fazer referência à disciplina do impulso (hormê), também comumente associada a Epicteto (cf. Diatribes de Epicteto III.2.1-2). Além disso, o fragmento 44 revela que o ensino de filosofia conferido por Musônio aos seus alunos incluía o estudo de problemas lógicos e de sofismas.

\section{Fragmento 22 (Estobeu 3.1.48 = 3.1.77 - Capítulo 1: Sobre a VirTude)}

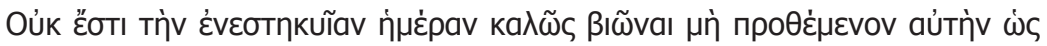

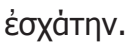

Náo se vive belamente o dia que nasce sem propô-lo como o último.

\section{Fragmento 23 (Estobeu 3.2.31 - Capítulo 2: Sobre o mal)}

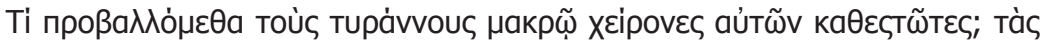
yàp ò

Por que acusamos os tiranos, quando já nos tornamos piores do que eles? Pois possuímos impulsos semelhantes em fortunas dessemelhantes.

\footnotetext{
${ }^{23}$ HENSE. Musonii Rufi Reliquiae. Leipzig 1905. Outros trabalhos importantes e recentes que tratam de Musônio são: LAURENTI. Musonio, maestro di Epitteto. In: ANRW 2.36.3, 1989, p. $2105-$ 2146; FRANCIS, J. A. Subversive virtue: asceticism and authority in the second-century pagan world. University Park, Pa., Pennsylvania State University Press. 1995, p. 11-16.

${ }^{24}$ LUTZ, C. Musonius Rufus: The Roman Socrates. In: Yale Classical Studies, Volume X. A. R. Bellinger (Ed.). Yale: Yale University Press, 1947; KING, C. Musonius Rufus: Lectures and Sayings. William B. Irvine (ed.). Seatle: CreateSpace, 2011.
} 
Fragmento 24 (Estobeu 3.5.21 - Capítulo 5: Sobre o autocontrole)

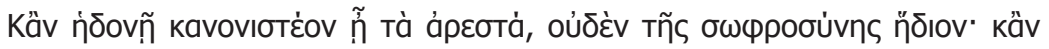

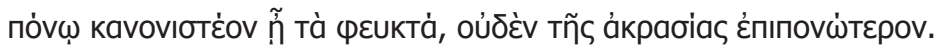

Caso as coisas agradáveis sejam medidas pelo prazer, nada <será $>$ mais prazeroso que a moderação. Caso as coisas a serem evitadas sejam medidas pela dor, nada <será> mais doloroso que a incontinência.

Fragmento 25 (Estobeu 3.6.21 - Capítulo 6: Sobre a autoindulgência)

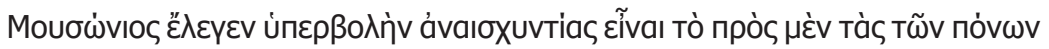

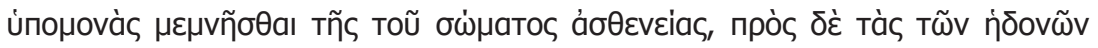

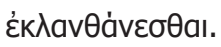

Musônio dizia ser o extremo da falta de vergonha lembrar-se da fraqueza do corpo em relação à capacidade de suportar labores, mas se esquecer totalmente $<$ da mesma fraqueza $>$ em relação à capacidade de suportar prazeres.

Fragmento 26 (Estobeu 3.6.22)

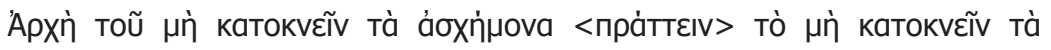

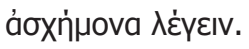

O princípio do não se abster de fazer coisas vergonhosas é o não se abster de dizer coisas vergonhosas.

Fragmento 27 (Estobeu 3.7.22 - Capítulo 7: Sobre a Coragem)

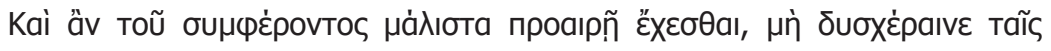

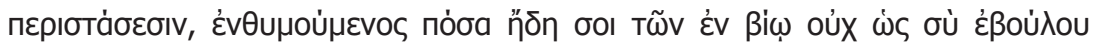

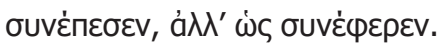


E, caso escolheres ater-te sobretudo ao que é útil, não sintas aborrecimento diante das dificuldades, ponderando quantas coisas na vida já te ocorreram não como desejavas, mas como era útil.

\section{Fragmento 28 (Estobeu 3.7.23)}

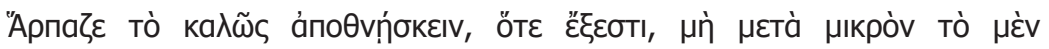

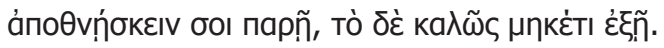

Agarra a bela morte enquanto ela for possível: que, um pouco depois, não dependa de ti a morte, mas a bela morte não seja mais possível.

\section{Fragmento 29 (Estobeu 3.7.24)}

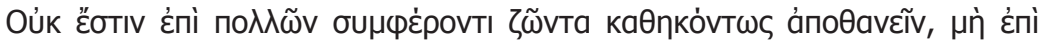

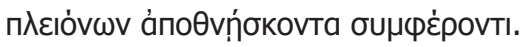

Não é apropriado morrer ao que é útil a muitos; a não ser que, morrendo, seja útil a muitos mais.

Fragmento 30 (Estobeu 3.31.6)

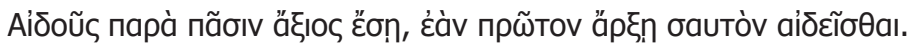

Merecerás respeito da parte de todos, caso primeiro comeces a respeitar a ti mesmo.

Fragmento 31 (Estobeu 4.7.14 - Capítulo 7: Conselho sobre o reinado)

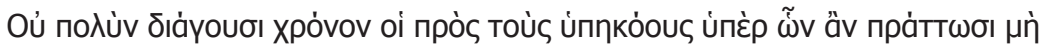

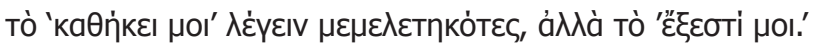


Não perduram por muito tempo os que, em relação aos súditos, sobre as coisas que façam, não tenham praticado < dizer> "É-me apropriado", mas "É-me possível".

\section{Fragmento 32 (Estobeu 4.7.15)}

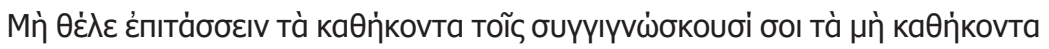
пра́ттоVTI.

Não queiras prescrever as açóes apropriadas aos que sabem que praticas as <açóes> inapropriadas.

\section{Fragmento 33 (Estobeu 4.7.16)}

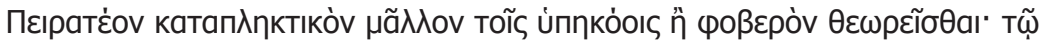

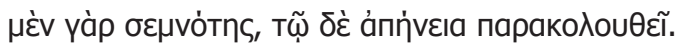

Deve-se tentar antes parecer impressivo que temível aos súditos: pois ao impressivo liga-se inseparavelmente a reverência; mas ao temível, a rudeza.

Fragmento 34 (Estobeu 4.31d.119 - Capítulo 31: Sobre a RiQueza)

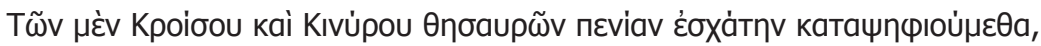

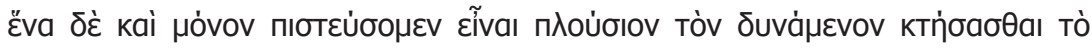

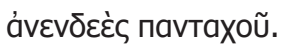

Os tesouros de Croesus e Cinyra decretaremos como extrema pobreza. Somente um creremos ser rico: aquele que, onde quer que esteja, é capaz de manter-se prescindindo de tudo.

Fragmento 35 (Estobeu 4.51.25 - Capítulo 51: Sobre A morte)

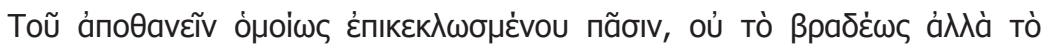

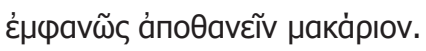


Sendo destinado igualmente a todos morrer, é feliz quem morre não tardiamente, mas com distinção.

\section{Fragmento 36 (Plutarco, Moralia, 453 D-E)}

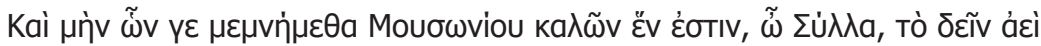

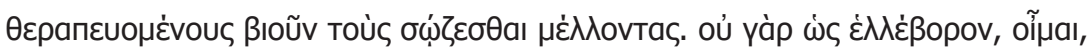

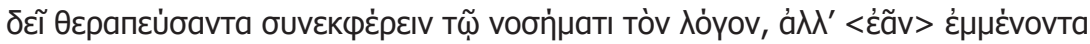

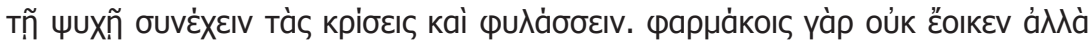

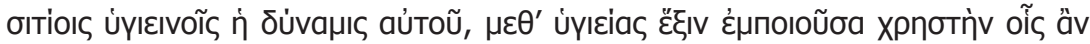

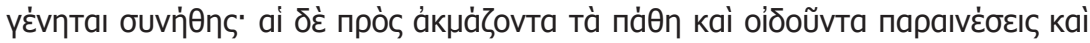

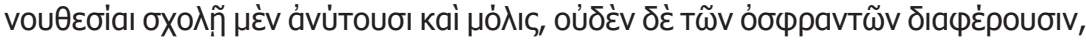

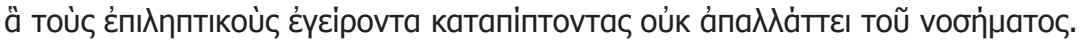

Certamente uma das belas coisas que lembramos de Musônio, ó Sulla, <é> o precisar sempre viver se cuidando os que desejam preservar-se. Pois não se deve descartar a razão junto com a doença, ao curar, como é o caso do heléboro. Mas, permanecendo na alma, <a razão deve> agrupar e guardar os juízos. Pois o poder dela não se parece com os remédios, mas com os alimentos saudáveis, produzindo, com a saúde, boa disposição naquele que se tenha habituado <a ela>. Mas exortaçóes e admoestaçóes < dirigidas> a quem tem as paixôes no ápice e fermentando realizam pouco e com dificuldade. Não diferem <tais admoestaçôes> dos sais odoríficos que despertam os epiléticos que desmaiam: não removem a doença.

\section{Fragmento 37 (Plutarco, Moralia, 830 в)}

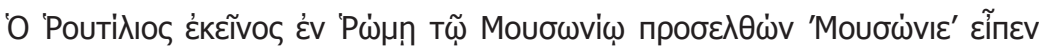

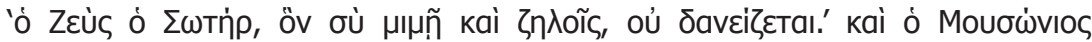

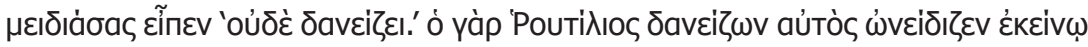

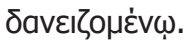

Aquele Rutílio ${ }^{25}$, em Roma indo ter com Musônio, disse: "Musônio! Zeus libertador, o qual imitas e louvas, não concede empréstimos”. E

${ }^{25}$ Públio Rutílio Lupo, gramático romano do século I (cf. QUINTILIANO, 830b) . 
Musônio, rindo, disse: "Nem os toma". Pois o próprio Rutílio, concedendo um empréstimo a Musônio, estava reprovando-o por tomá-lo.

Fragmento $38^{26}$ (Estobeu 2.8.30 - Capítulo 8: SObre as Coisas QUe estáo SOB NOSSO CONTROLE)

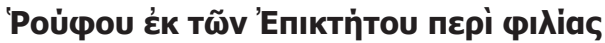

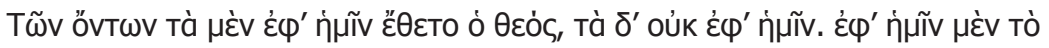

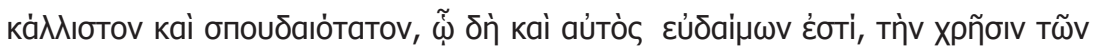

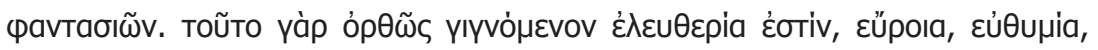

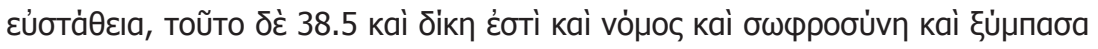

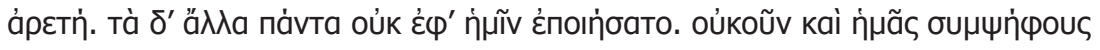

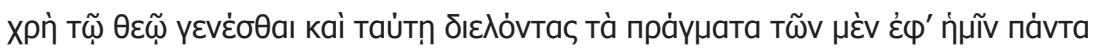

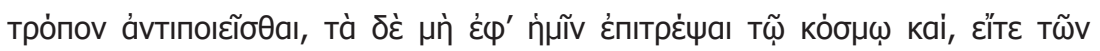

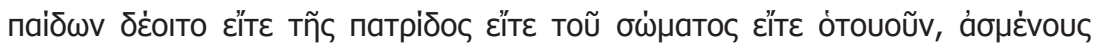
парах

\section{De Rufo: a Partir dos ditos de EpICteto sobre a AMIZAde}

Das coisas, umas Deus pôs sob nosso controle ${ }^{27}$; outras não. Sob nosso controle está a que é melhor e excelente, pela qual mesmo Deus é feliz: o uso das representaçóes. Pois, tornando-se reto, este <confere> liberdade, serenidade, confiança, firmeza, bem como justiça, lei, prudência - a excelência com um todo. Mas as demais coisas não foram feitas sob nosso controle. Portanto, é preciso nos harmonizarmos com Deus e, dividindo as coisas desse modo, aplicar-nos em todos os sentidos às que estão sob nosso controle. E as que não estão, transferir para o Cosmos, mesmo que seja preciso ceder, de bom grado, ou os filhos, ou a pátria, ou o corpo, ou o que for.

\footnotetext{
${ }^{26}$ Esse fragmento aparece simultaneamente entre os fragmentos de Epicteto (SCHENKL, 38).

${ }^{27}$ A expressão ephí hēmîn não possui equivalente direto em nossa língua. Literalmente significando "o que está sobre nós", é comumente é traduzida, nas línguas modernas, por expressóes equivalentes a "o que depende de nós" ou, como o fizemos aqui, "o que está sob nosso controle".
} 
Fragmento $39^{28}$ (Estobeu 3.19.13 - CAPítulo 19 - Da IRA)

\section{'Poù}

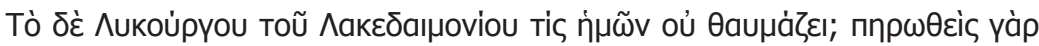

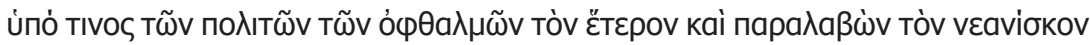

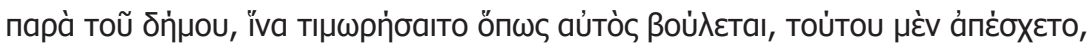

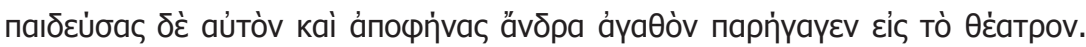

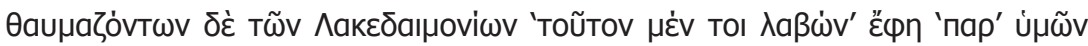

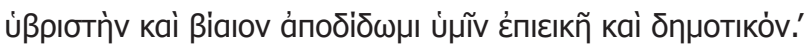

\section{De Rufo: a Partir dos ditos de Epicteto sobre a AMizade}

Quem de nós não se espanta com Licurgo ${ }^{29}$, o lacedemônio? Pois tendo sido mutilado em um dos olhos por um dos concidadáos e tendo recebido do povo o jovem <agressor> para vingar-se como desejasse, absteve-se disso. Mas, educando-o e tornando-o homem bom, levou-o lado a lado ao teatro. Quando os lacedemônios se espantaram, <Licurgo >, compreendendo <o espanto>, disse-lhes: "Após recebê-lo de vós desmedido e agressivo, devolvo-o a vós moderado e humanizado".

Fragmento $40^{30}$ (Estobeu 3.20.60 - CApÍtulo 20: SOBRE A IRA)

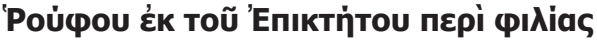

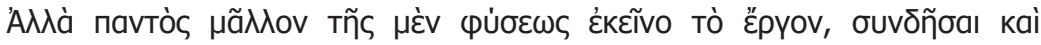

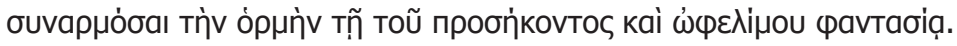

\section{De Rufo: a Partir dos ditos de Epicteto sobre a AMIZAde}

Esta é, entre todas, a maior ação da natureza: combinar e conjuntamente harmonizar o impulso à representação do que é apropriado e útil.

\footnotetext{
${ }^{28}$ Esse fragmento aparece simultaneamente entre os fragmentos de Epicteto (SCHENKL, 67).

${ }^{29}$ Célebre legislador espartano (Ca. 820-730 a.C.).

${ }^{30}$ Esse fragmento aparece simultaneamente entre os fragmentos de Epicteto (SCHENKL, frag. 169).
} 
Fragmento $41^{31}$ (Estobeu 3.20.61 - CApítulo 20: SOBRe A IRA)

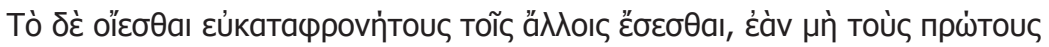

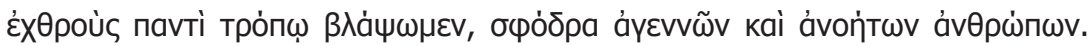

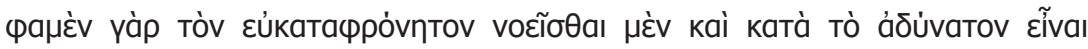

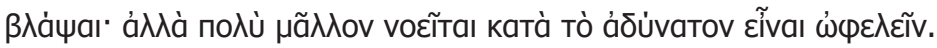

É de homens sumamente sórdidos e tolos pensar que seremos desprezíveis aos demais se náo causarmos dano de todas as maneiras aos nossos maiores inimigos. Dizemos que o desprezível é concebido também como incapaz de causar dano, mas é muito melhor concebê-lo como incapaz de ser benéfico.

Fragmento $42^{32}$ (Estobeu 4.44.60 - QUe OS SERES HUMANOS DEVEM SUPORTAR O QUE QUER QUE LHES ACONTEÇA E DEVEM VIVER VIRTUOSAMENTE)

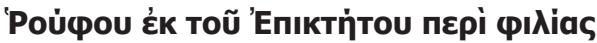

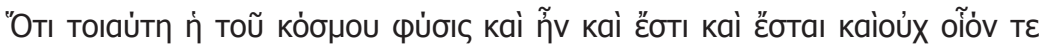

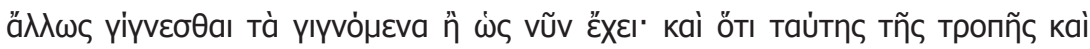

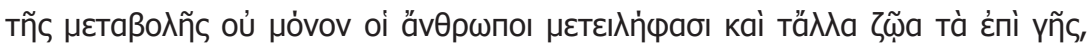

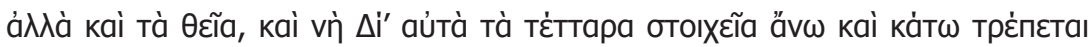

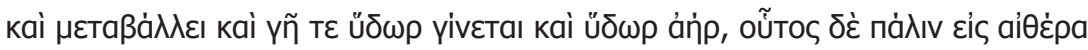

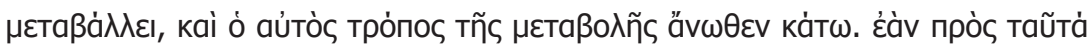

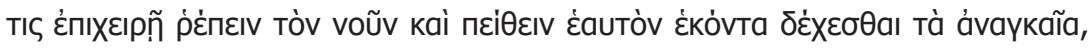

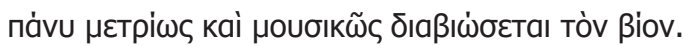

\section{De Rufo: A PARTIR dos ditos de EPICTETo sobre a AMIZAde}

Porque tal é a natureza do Cosmos, e assim era e será, e não é possível que os acontecimentos advenham de outra maneira senão como agora são. $\mathrm{E}$ não somente os homens e os outros animais sobre a terra partilham esse ciclo e essa transformação, mas também <as coisas> divinas. E, por Zeus, mesmo os quatro elementos voltam-se para cima e para baixo, transformando-se. Da terra advém a água; da água, o ar, que, de novo, transforma-se em éter, e essas

\footnotetext{
${ }^{31}$ Esse fragmento aparece simultaneamente entre os fragmentos de Epicteto (SCHENKL, frag. 70).

${ }^{32}$ Esse fragmento aparece simultaneamente entre os fragmentos de Epicteto (SCHENKL, 134).
} 
mesmas transformaçốes <ocorrem também> de cima para baixo. Passará sua vida com medida e com harmonia quem tentar voltar o pensamento para essas coisas e voluntariamente persuadir-se a aceitar a necessidade.

\section{Fragmento 43 (Epicteto, Diatribes 1.1.26)}

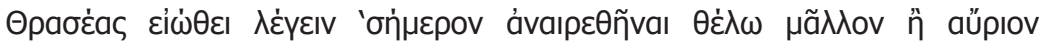

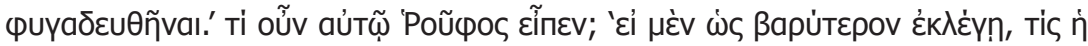

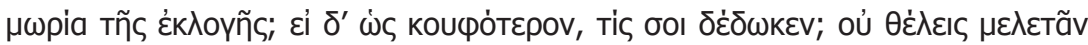

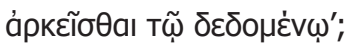

Tráseas ${ }^{33}$ costumava dizer: "Prefiro ser morto hoje a ser exilado amanhâ". $\mathrm{O}$ que então que lhe disse Rufo? "Se escolheres a morte como a pena mais pesada, que loucura de escolha! Mas, se como a mais leve, quem te permitiu fazer tal escolha? Não desejas praticar o contentar-te com o que te foi dado?”

\section{Fragmento 44 (Epicteto, Diatribes 1.7.30-33)}

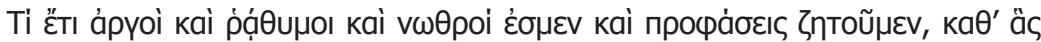

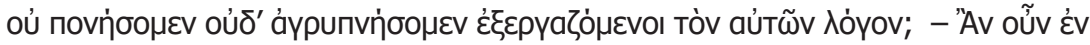

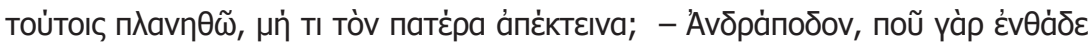

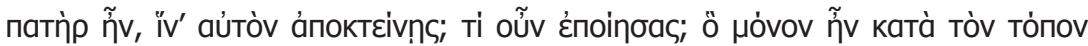

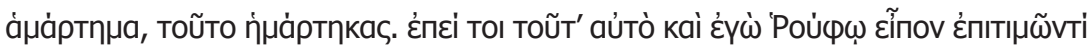

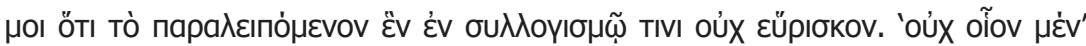

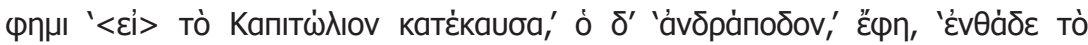

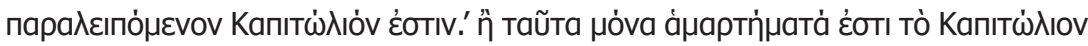

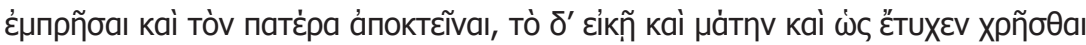

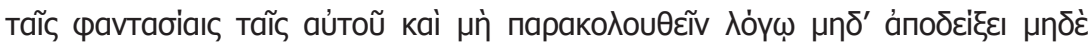

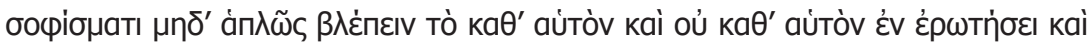

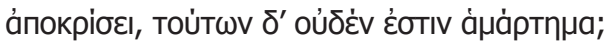

Por que ainda somos preguiçosos, insolentes e lerdos, e buscamos pretextos para não nos fatigar nem velar, cultivando a nossa própria razão?

${ }^{33}$ Senador romano que se notabilizou por sua oposição a Nero e por seu interesse pela filosofia estoica. 
<Epicteto:> "Mas se eu me confundir nessas coisas, não matarei meu pai, não é mesmo?" <Musônio:> "Escravo, onde, aí, está o teu pai, para que o mates? O que fizeste? O único erro que há nesse assunto, tu o cometes". Pois te digo o mesmo que eu disse a Rufo, quando me criticou porque náo descobri uma omissão em um raciocínio: "Com certeza - disse eu - não é como se eu tivesse posto fogo no Capitólio". E ele me disse: "Escravo, a omissão aqui é o Capitólio". Ou somente são erros incendiar o Capitólio e matar o pai, mas servir-se das próprias representaçóes ao acaso e de modo vão e confuso e não compreender <nem> um raciocínio, nem uma demonstração, nem um sofisma, nem, em resumo, ver no diálogo o que é consistente e o que não o é - nenhuma dessas coisas é um erro?

\section{Fragmento 45 (EPicteto, Diatribes 1.9.29-32)}

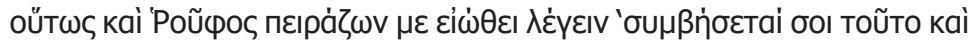

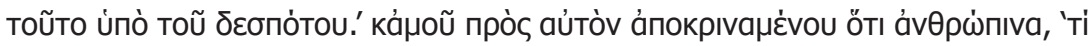
oũv' ह̌

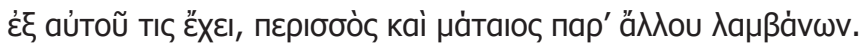

Desse modo também Rufo, testando-me (29), costumava dizer "Teu senhor te fará isto ou aquilo". E eu respondia a ele que (30) "São coisas que acontecem aos homens". "E entáo?" < dizia ele> "Ainda pedirei a ele (31) o que posso obter diretamente de ti?" (32) Pois é supérfluo e vão tomar de outro o que se pode obter de si mesmo.

\section{Fragmento 46 (Epicteto, Diatribes 3.6.9-10)}

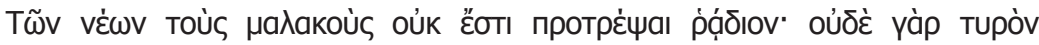

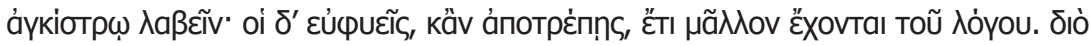

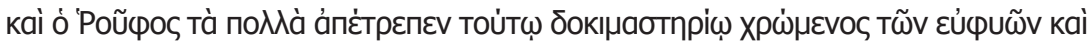

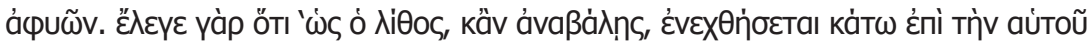

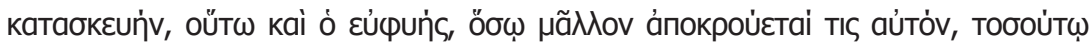

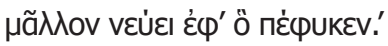

Dos jovens, não é fácil atrair os que são moles, pois não se prende um $<$ pedaço de> queijo com um anzol. Mas os naturalmente bem constituídos, se tu afastá-los, ainda mais se prendem à razão. Por isso, Rufo na maioria 
das vezes os afastava, fazendo uso do teste dos bem constituídos e dos mal constituídos. Pois dizia que "A pedra, mesmo quando a lançares para cima, será conduzida para baixo por causa de sua constituição. Assim também é o bem constituído: quanto mais alguém o afasta, tanto mais se inclina para aquilo que <lhe> é natural”.

\section{Fragmento 47 (Epicteto, Diatribes 3.15.14)}

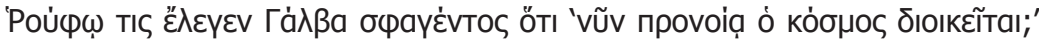

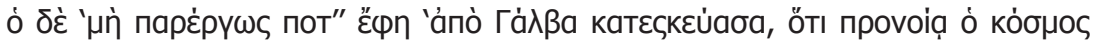
ठıоккетта।;'

Quando Galba foi assassinado, alguém indagou a Rufo: "O Cosmos ainda é administrado pela Providência?” E Rufo disse: "Mas, mesmo de modo incidental, eu provei ${ }^{34}$, baseado em Galba, que o Cosmos é administrado pela Providência?"

Fragmento 48 (Epicteto, Diatribes 3.23.29)

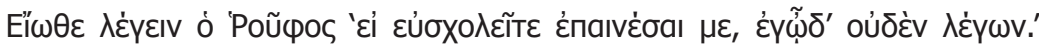

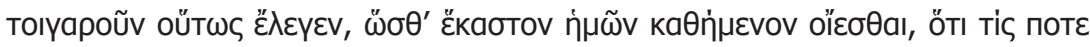

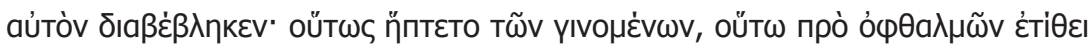
тà ह̇кáoтоu какá.

Costumava dizer Rufo: "Se tens bastante tempo livre para elogiar-me, não estou dizendo nada < de útil>”. Então falava de modo que cada um de nós, sentados, pensava que alguém alguma vez o denunciara. Desse modo, percebia os acontecimentos. Desse modo, colocava os males de cada um diante dos olhos.

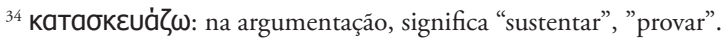




\section{Fragmento 49 (Aulus Gellius, 5.1)}

\section{QUOD MUSONIUS PHILOSOPHUS REPREHENDIT INPROBAUITQUE LAUDARI} PHILOSOPHUM DISSERENTEM A UOCIFERANTIBUS ET IN LAUDANDO GESTIENTIBUS.

*** Musonium philosophum solitum accepimus. 'Cum philosophus' inquit 'hortatur, monet, suadet, obiurgat aliudue quid disciplinarum disserit, tum, qui audiunt, si de summo et soluto pectore obuias uulgatasque laudes effutiunt, si clamitant etiam, si gestiunt, si uocum eius festiuitatibus, si modulis uerborum, si quibusdam quasi fritamentis orationis mouentur, exagitantur et gestiunt, tum scias et qui dicit et qui audiunt frustra esse neque illi philosophum loqui, sed tibicinem canere. Animus' inquit 'audientis philosophum, <dum>, quae dicuntur, utilia ac salubria sunt et errorum atque uitiorum medicinas ferunt, laxamentum atque otium prolixe profuseque laudandi non habet. Quisquis ille est, qui audit, nisi ille est plane deperditus, inter ipsam philosophi orationem et perhorrescat necesse est et pudeat tacitus et paeniteat et gaudeat et admiretur, uarios adeo uultus disparilesque sensus gerat, proinde ut eum conscientiamque eius adfecerit utrarumque animi partium aut sincerarum aut aegrarum philosophi pertractatio.' Praeterea dicebat magnam laudem non abesse ab admiratione, admirationem autem, quae maxima est, non uerba parere, sed silentium. 'Idcirco' inquit 'poetarum sapientissimus auditores illos Vlixi labores suos inlustrissime narrantis, ubi loquendi finis factus, non exsultare nec strepere nec uociferari facit, sed consiluisse uniuersos dicit quasi attonitos et obstupidos delenimentis aurium

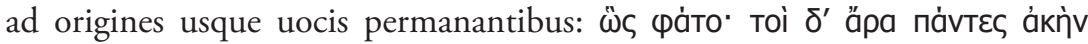

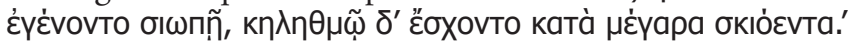

Que o FILÓSOFo MusôNio REPREENdeU E DESAPRovou SER Elogiado UM FILÓSOFO, ENQUANTO DISCURSA, POR PESSOAS QUE GRITAM E GESTICULAM ENQUANTO O ELOGIAM.

(1) Ouvimos que o filósofo Musônio comumente $<\ldots>^{35}$ "Quando o filósofo exorta, admoesta, persuade, reprova, ou $<$ faz $>$ outra coisa que o ensino tenha prescrito, se, então, os ouvintes bradam, de peito aberto e em alta voz, elogios óbvios e vulgares; se, pelos encantos de sua voz, pelo ritmo das palavras, por certa musicalidade de seu discurso, são movidos, exaltados e gesticulam,

${ }^{35}$ Lacuna do texto latino. 
então saibas também que tanto o que fala quanto os que ouvem estão no erro, e que naquele lugar não fala um filósofo, mas toca uma flauta”. Diz $<$ Musônio > também: "Ao espírito daquele que ouve um filósofo, na medida em que as coisas ditas são úteis e saudáveis e trazem remédios para os erros e para os vícios, não se proporciona relaxamento nem ócio para <permitir-lhe realizar> elogios prolixos e profusos. Quem quer que seja o ouvinte, a não ser que esteja completamente corrompido, é necessário, enquanto fale o filósofo, que estremeça, que tacitamente se envergonhe, que se arrependa, que se admire, que se alegre, e mesmo que assuma várias expressóes faciais e díspares emoções, conforme o detalhado tratamento do filósofo tenha afetado a ele e sua ciência de cada uma das partes de sua alma, sejam as saudáveis, sejam as enfermas". Além disso, <Musônio > dizia que o grande elogio não está ausente da admiração, porém a admiração, no grau máximo, produz não palavras, mas silêncio. "Por essa razão", diz <Musônio>, "o mais sábio dos poetas, ao $<$ fazer> Ulisses narrar com distinção os seus trabalhos, quando se dá o fim da fala, não faz os ouvintes exultarem, nem fazerem barulho, nem gritarem, mas diz <que> quedaram em silêncio, como se atônitos e estupefatos pelo encantamento dos ouvidos, que afeta até a fonte da fala: "Assim falou Ulisses, e, na sala cheia de sombra, todos se mostravam encantados e permaneciam imóveis e em silêncio". (Odisséia, 13.1) ${ }^{36}$

\section{Fragmento 50 (Gellius 9.2.8-10: sob o título: Com que palavras Herodes ÁtICO CRITICOU UM COLEGA QUE ASSUMIRA NOME E MODOS DE FILÓSOFO POR MEIO DE FALSO VESTIR-SE E MOSTRAR-SE)}

Tum nos aspiciens, qui eum sectabamur: 'Musonius' inquit 'aeruscanti cuipiam id genus et philosophum sese ostentanti dari iussit mille nummum, et cum plerique dicerent nebulonem esse hominem malum et malitiosum et nulla re bona dignum, tum Musonium subridentem dixisse aiunt: a̋६ıৎৎ oũv غ̇oTıv ápyupiou.

Enquanto observava a nós, que o seguíamos, <Herodes Ático ${ }^{37}>$ disse: Musônio ordenou dar mil sestércios a alguém desse gênero ${ }^{38}$ que pedia

\footnotetext{
36 Tais versos da Odisséia na tradução de Antônio Pinto de Carvalho (cf. HOMERO. Odisséia. São Paulo: Abril Cultural, 1981, p. 120).

37 Famoso sofista da Segunda Sofística, com quem Aulo Gélio estudou em Atenas. Viveu entre 101 e 170 .

38 Gélio mencionara pouco antes que um homem, fazendo-se passar por filósofo, acabara de pedir dinheiro a Herodes Ático, em razão do que este se recordou do episódio com Musônio.
} 
dinheiro e que se exibia como filósofo, e quando muitos disseram ser aquele um homem desprezível, mau e malicioso, e que nada merecia de bom, dizem que Musônio, sorridente, falou: "Merece, pois, o dinheiro".

Fragmento 51 (Gellius 16.1 sob o título "Palavras gregas do filósofo MUSÔNIO QUE MERECEM SER OUVIDAS E SEGUIDAS")

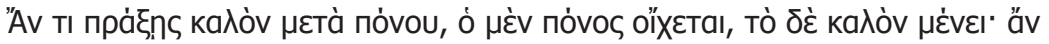

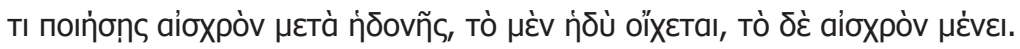

Caso faças algo nobre com sofrimento, o sofrimento passa, mas a nobreza permanece. Caso realizes algo vergonhoso com prazer, o prazer passa, mas a vergonha permanece.

Fragmento 52 (Gellius 18.2.1 sob o titulo "Dos tipos de Questóes Que USÁVAMOS DURANTE as SATURNÁLIAS EM Atenas')

Saturnalia Athenis agitabamus hilare prorsum ac modeste, non, ut dicitur, remittentes animum - nam 'remittere' inquit Musonius 'animum quasi amittere est' -, sed demulcentes eum paulum atque laxantes iucundis honestisque sermonum inlectationibus.

Passávamos a saturnalia em Atenas de modo alegre e disciplinado, não, como é dito, relaxando o espírito, pois "relaxar o espírito", diz Musônio, "é quase pô-lo a perder" 39 -, mas afagando-o um pouco e estendendo-o por meio dos agradáveis e dignos encantos da conversação.

\section{Fragmento 53 (Aelius Aristides, Oraçóes LII)}

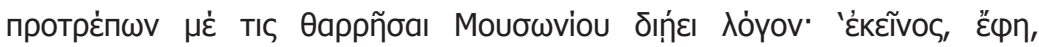

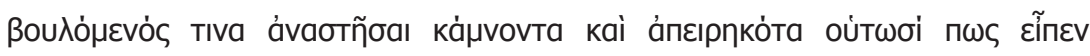

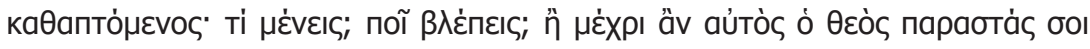

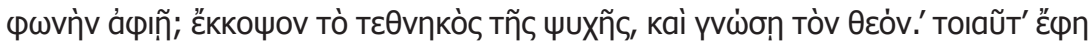

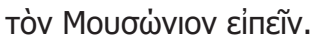

39 Musônio faz um jogo de palavras: remittere (relaxar) é quase amittere (perder). 
Alguém, buscando encorajar-me, usou as palavras de Musônio. Ele, disse, desejando que alguém, cansado e derrotado, se soerguesse, falava do seguinte modo, censurando-o: "Por que estás parado? Pelo que esperas? Que o próprio Deus, estando ao teu lado, dirija-te a palavra? Corta a parte morta da tua alma, e conhecerás Deus". Coisas tais dizia falar Musônio.

\section{REFERÊNCIAS}

AULO GÉLIO. Attic Nights. Volumes I, II, III. Trad. J. C. Rolfe. Harvard: Loeb Classical Library, 1927.

DINUCCI, A. Introdução ao Manual de Epicteto. 3 ed. São Cristóvão: EdiUFS, 2012.

DION CÁSSIO. Roman History. Trad. Cary; Foster. Harvard: Loeb Classical Library, 1914-1927.

EPICTETO. The Discourses as reported by Arrian (Books I, II, III \& IV); Fragments; Encheiridion. Trad. W. A. Oldfather. Cambridge: Loeb, 2000.

EPICTETO. O Encheirídion de Epicteto. Trad. Aldo Dinucci; Alfredo Julien. São Cristóvão: EdiUFS, 2012.

EPICTETO. Testemunhos e Fragmentos. Trad. Aldo Dinucci; Alfredo Julien. São Cristóvão: EdiUFS, 2008.

ESTOBEU. Florilegium, vol I e II. Augustus Meineke (ed.). Lipsiae: Taubner, 1855.

FILOSTRATO. Apollonius of Tiana, Volumes I, II, III. Trad. C. P. Jones. Harvard: Loeb Classical Library, 2005-2006.

FRANCIS, J. A. Subversive virtue: asceticism and authority in the second-century pagan world. University Park, Pa: Pennsylvania State University Press, 1995.

HENSE. Musonii Rufi Reliquiae. Leipzig 1905.

HOMERO. Odisséia. Trad. Antônio Pinto de Carvalho. São Paulo: Abril Cultural, 1981.

KING, C. Musonius Rufus: Lectures and Sayings. William B. Irvine (ed.). Seattle: CreateSpace, 2011.

LAURENTI. Musonio, maestro di Epitteto. In: Aufstieg und Niedergang der römischen Welt, 2.36.3, 1989, p. 2105-2146.

LUTZ, C. Musonius Rufus: The Roman Socrates. IN: Yale Classical Studies, Volume X. A. R. Bellinger (ed.). Yale: Yale University Press, 1947.

PLÍNIO, O JOVEM. Letters, Volumes I, II. Trad. B. Radice. Harvard: Loeb Classical Library, 1969. 
PLUTARCO. On the Control of Anger. Trad. W. C. Helmbold. Harvard: Loeb Classical Library, 1939.

QUINTILIANO. The Orator's Education, VolumeS I, II, III, IV, V. Trad. D. A. Russel. Harvard: Loeb Classical Library, 2002.

SCHENKL H. Die Epiktetishen Fragmente. In: Sitzungsberichte der philos. - hist. Calsse der K. Akad. der Wiss. Viena, 115 (1888), 443-546.

SUIDAS. Suidae lexicon. Ada Adler (ed.). Leipzig: 1928-1938.

TÁCITO. Annals, Volumes I, II. Trad. Jackson John. Harvard: Loeb Classical Library, 1937.

TÁCITO. Histories, Volumes I, II. Trad. Clifford, M; J. Jackson. Harvard: Loeb Classical Library, 1925-1931.

Recebido em: 10.03.2012

Aceito em: 04.06.2012 